\title{
Business cycles, international trade and capital flows: evidence from Latin America
}

\author{
Guglielmo Maria Caporale • Alessandro Girardi
}

Received: 17 January 2014 / Accepted: 18 December 2014 / Published online: 6 February 2015

C The Author(s) 2015. This article is published with open access at Springerlink.com

\begin{abstract}
This paper adopts a flexible framework to assess both short- and long-run business cycle linkages between the Latin American (LA) bloc and the four largest economies in the world (namely the US, the Euro area, Japan and China) over the period 1980:I-2011:IV. The result indicates that the LA region is largely dependent on external developments, especially in the years after the great recession of 2008 and 2009. The trade channel appears to be the most important source of business cycle co-movement, whilst capital flows are found to have a limited role, especially in the very short run.
\end{abstract}

Keywords International business cycle · Latin America · VAR models · Trade and financial linkages

JEL Classification $\quad \mathrm{C} 32 \cdot \mathrm{E} 32 \cdot \mathrm{F} 31 \cdot \mathrm{F} 41$

\section{Introduction}

It is well known that macroeconomic volatility generates both economic and political uncertainty with detrimental effects on investment and consumption plans and, ultimately, future economic growth (Acemoglu et al. 2003) and aggregate welfare (Athanasoulis and van Wincop 2000). There is therefore considerable interest, among

G. M. Caporale $(\varangle)$

Department of Economics and Finance, Brunel University, London, UK

e-mail: Guglielmo-Maria.Caporale@brunel.ac.uk

A. Girardi

Econometric Studies and Economic Forecasting Division,

Italian National Institute of Statistics, Rome, Italy

e-mail: agirardi@ istat.it 
academics as well as policy-makers, in shedding light on the sources of output fluctuations, especially in the new economic environment characterised by a much greater role played by emerging market countries and by low growth and uncertainty in advanced economies.

Economic theory does not provide unequivocal predictions: International financial and trade linkages could result either in a higher or a lower degree of business cycle comovement depending on whether or not demand- and supply-side (as well as wealth) effects dominate over increased specialisation of production through the reallocation of capital (Baxter and Kouparitsas 2005; Kose et al. 2003, 2012). This cannot be established ex-ante: It is essentially an empirical question.

A knowledge of cross-country spillover effects is, especially relevant for emerging countries because of their higher degree of volatility compared to more mature economies. According to Loayaza et al. (2007), both internal and external factors explain why emerging economies are so volatile: (1) the instrinsic instability induced by the development process itself; (2) the lack of effective mechanisms (such as well functioning financial markets and proper stabilisation macroeconomic policies) to absorb external fluctuations; and (3) the exposure to exogenous shocks in the form of sudden capital inflows/outflows and/or large changes in the international terms of trade.

The Latin American (LA) economies in particular have experienced a remarkable sequence of booms and busts in the last three decades. After the debt crisis of the 1980s, most countries in the region benefited from huge capital inflows (with a resulting high growth rate) until the Russian crisis in the late nineties led to their sudden drying up; then, in the early years of the following decade higher liquidity, a dramatic rise in commodity prices and low risk premia created a particularly favourable macroeconomic and financial environment in the region and generated again robust growth (Österholm and Zettelmeyer 2007; Izquierdo et al. 2008); therefore, the question has been asked whether there has been a decoupling of the business cycle in the industrialised countries and the LA region, respectively, the latter having become an increasingly autonomous source of growth for the world economy.

The present study assesses the relative importance of external as well as regional and country-specific factors in explaining business cycle fluctuations in the LA region as a whole over the last three decades. It also investigates the role of bilateral trade flows and financial linkages in business cycle co-movements between the LA region and its main economic partners. More specifically, the analysis is based on the framework introduced by Diebold and Yilmaz (2012) and uses a very flexible empirical model to examine the propagation of international business cycles without any restrictions on the directions of short- and long-run spillovers or the nature of the propagation mechanism itself.

Using quarterly data from 1980:I to 2011:IV, we document that the LA region can be characterised as a small open economy largely dependent on external developments. This applies, especially to the the years following the great recession of 2008 and 2009 , contradicting the so-called decoupling hypothesis. In particular, our findings imply that the goods trade channel is the most important source of these linkages. Capital flows also affect business cycle co-movements, but their role is limited, especially in the very short run. The disaggregate analysis focusing on their components (debt, portfolio equity and foreign direct investment flows) reveals a negative effect of 
portfolio equity flows on the degree of business cycle synchronisation, as predicted by standard international real business cycle models with complete markets. By contrast, short-term capital and foreign direct investment flows reinforce in the short run the role of the trade channel and make the LA region more vulnerable to shocks from abroad, consistently with recent empirical evidence (e.g. Imbs 2010).

The layout of the paper is as follows. Section 2 describes the methodology used to assess the propagation mechanism of international business cycles. Section 3 describes the data and presents the empirical results based on the forecast error variance decompositions for the LA bloc. Section 4 provides evidence on the role of financial and trade linkages. Section 5 offers some concluding remarks. The "Appendix" provides further evidence for the individual LA economies.

\section{The methodology}

\subsection{The empirical framework}

We focus on output growth to analyse the dynamic relationships between the LA region and the rest of the world. Given the increasing degree of integration of the global economy, it is essential to consider possible linkages with a number of foreign economies. It is equally important to allow for time variation, since a fixed parameter model is not likely to capture possibly important changes in the business cycle propagation mechanisms resulting from globalisation. ${ }^{1}$

Consequently, the modelling approach chosen here differs from previous ones in two ways. First, it is flexible enough to accommodate possible nonlinear shifts in the propagation of international business cycles; second, it is based on analysing linkages with the output growth rate of various economies outside the LA region rather than a number of macroeconomic variables for a single foreign country (typically the US). Therefore, we include the US as the main driving force behind business cycles comovements in the LA region (see the literature on the US "backyard", e.g. Ahmed 2003; Canova 2005; Caporale et al. 2011), but also the Euro area because of its historical trade linkages with the LA region, as well as Japan (given the financial linkages documented by Boschi 2012; Boschi and Girardi 2011) and China, whose trade linkages with the LA region have become much stronger in recent years (Cesa-Bianchi et al. 2011).

As in Diebold and Yilmaz (2012), the econometric framework is based on the following covariance-stationary Vector AutoRegression (VAR) model

$$
y_{t}^{(k)}=\sum_{j=1}^{p} \Gamma_{j}^{(k)} y_{t-j}^{(k)}+u_{t}^{(k)}
$$

\footnotetext{
1 Including additional variables (such as interest rates, exchange rates, consumption or investment) for a wide range of countries would result in a system whose dimensions would not be manageable in the standard Vector AutoRegression (VAR) approach followed here. Even advanced econometric approaches, such as the Global VAR (see Cesa-Bianchi et al. 2011; Boschi and Girardi 2011) or dynamic factor models (as in Kose et al. 2012, among others), would not be a fully satisfactory modelling strategy since they belong to the class of (linear) time-invariant models.
} 
in its moving average representation

$$
y_{t}^{(k)}=\sum_{j=0}^{\infty} \Psi_{j}^{(k)} u_{t-j}^{(k)}
$$

where $\Psi_{i}^{(k)}=\sum_{j=1}^{p} \Gamma_{i}^{(k)} \Psi_{i-j}^{(k)}, p$ is the order of autoregression, the vector $y$ includes the $n$ endogenous variables of the system, $t=1, \ldots, T$ indexes time, and $e$ is the vector of residuals, with $E\left[u_{t}^{(k)}\right]=0, E\left[u_{t}^{(k)}, u_{s}^{\prime(k)}\right]=\Sigma_{u}^{(k)}$ if $s=t$ and $E\left[u_{t}^{(k)}, u_{s}^{\prime(k)}\right]=0$ otherwise. All elements refer to the generic $k$ th estimation sample with window size of $\theta \leq T$ observations, so that if $\theta=T$ then $k=1$, whilst if $\theta<T$, model (1) involves $k=T-\theta+1$ different rolling estimates, where the sample initially spans the period from the first available observation to $\theta$, and then, both its starting and ending period is shifted forward by one datapoint at a time. As pointed out by Granger (2008), linear models with time-varying parameters are actually very general nonlinear models, and therefore, the chosen framework is ideally suited to analysing the issues of interest.

\subsection{Innovation accounting}

Examining all the effects of the lagged variables in a VAR model is often both difficult and unnecessary for the purposes of the analysis (Sims 1980). Rather, it is more convenient to resort to some transformations of the estimated model (1) in order to summarise the dynamic linkages among the $n$ variables under investigation. In the business cycle literature, a useful metric often used to measure the extent of business cycle synchronisation is the sum of the variance shares of different classes of shocks such as country-specific, regional or global sources of economic fluctuations (see Kose et al. 2012, among others). ${ }^{2}$

Since the reduced form residuals $u$ 's are generally correlated, a common practice to obtain uncorrelated shocks is to use the Choleski decomposition of $\Sigma_{u}^{(k)}$. Despite its straightforward implementation, this method has the drawback that it is sensitive to the ordering of the variables in the system, and therefore, all possible permutations should be considered when carrying out the dynamic simulations for a thorough assessment. A popular alternative is provided by the generalised forecast error variance (GFEV) decomposition (Pesaran and Shin 1998). This approach estimates the percentage of the variance of the $h$-step ahead forecast error of the variable of interest which is explained by conditioning on the non-orthogonalised shocks whilst explicitly allowing for contemporaneous correlations between these shocks and those to the other equations in the system

\footnotetext{
2 Note that the methodology used in Kose et al. (2012) differs from ours in that they compute the variance decomposition of the raw series of interest, whilst in the present paper, the forecast error variance decomposition is carried out. Therefore, whilst we analyse the innovation (or unsystematic) part of the series represented by the residual of the estimated model, they decompose its systematic part. The limitation of their approach, namely a Bayesian dynamic latent factor model, is that it does not allow the identification of the geographical origin of the factors affecting domestic business cycles, but rather of the world, region and country-specific components of a series.
} 


$$
\mathrm{GFEV}_{l, m, h}^{(k)}=\frac{1}{\sigma_{m, m}^{(k)}} \sum_{q=0}^{h}\left(e_{l}^{\prime} \Psi_{q}^{(k)} \Sigma_{u}^{(k)} e_{m}\right)^{2}
$$

where the selection vectors $e_{l}$ and $e_{m}$ have their $l$ th and $m$ th entries equal to one, respectively, with all other elements being zero, and $\sigma_{m, m}^{(k)}$ stands for the standard deviation associated to the $m$ th equation of the system.

Although the GFEV method does not allow a structural interpretation of the impulses, it overcomes the identification problem by providing a meaningful characterisation of the dynamic responses of the variables of interest to observable shocks. A further useful feature of this approach is its invariance to the ordering of the variables. Note, however, that owing to the possible non-diagonal form of matrix $\Sigma_{u}^{(k)}$, the sum over $m$ of the elements (3) need not be unity in the original formulation provided by Pesaran and Shin (1998). In order to be able to interpret the results, we rescale (3) using the total variance in the generalised rather than in the orthogonal case

$$
\xi_{l, m, h}^{(k)}=\frac{\frac{1}{\sigma_{m, m}^{(k)}} \sum_{q=0}^{h}\left(e_{l}^{\prime} \Psi_{q}^{(k)} \Sigma_{u}^{(k)} e_{m}\right)^{2}}{\sum_{m=1}^{n} \frac{1}{\sigma_{m, m}^{(k)}} \sum_{q=0}^{h}\left(e_{l}^{\prime} \Psi_{q}^{(k)} \Sigma_{u}^{(k)} e_{m}\right)^{2}}
$$

so that $\sum_{m=1}^{n} \xi_{l, m, h}^{(k)}=1$ (for all $k$ and $h$ ), that is, the sum of the variance decompositions in (4) are normalised to unity.

\subsection{Measuring spillover effects}

By computing the decomposition (4) for all variables in system (1) for a given recursion $k$ and for a given simulation horizon $h$, we obtain the following $n \times n$ matrix (the spillover table according to the terminology of Diebold and Yilmaz 2012), ${ }^{3}$ which makes it possible to measure to extent to which two or more variables of the system are connected to each other:

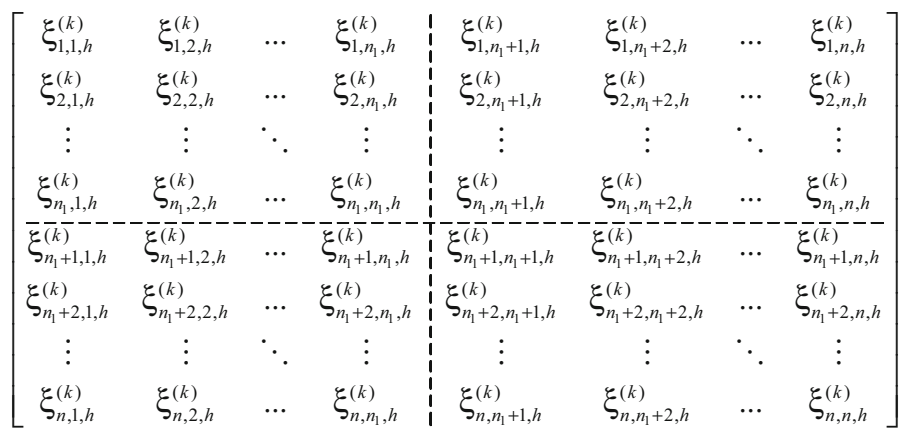

\footnotetext{
3 By construction, the elements in each row of (5) sum up to unity, so that the total variance of the system is equal to $n$.
} 
Diebold and Yilmaz (2012) show that a synthetic measure of the spillovers to (from) country $l$ from (to) all other countries can be obtained by summing by columns (rows) all the off-diagonal elements in the $l$ th row (column). We adapt their framework by dividing the variable of system (1) into two distinct subsets (which we label regional and external groups) with dimension of $n_{1}=6$ and $n-n_{1}=4$, respectively. More precisely, we define the region-specific shocks, $\gamma_{\text {reg, } h}^{(k)}$, as

$$
\gamma_{\mathrm{reg}, h}^{(k)}=\frac{1}{n_{1}} \sum_{l=1}^{n_{1}} \sum_{m=1}^{n_{1}} \xi_{l, m, h}^{(k)}
$$

whilst the aggregate external shocks (that is, the innovations originating outside the LA region) are computed as

$$
\gamma_{\mathrm{ext}, h}^{(k)}=\frac{1}{n_{1}} \sum_{l=1}^{n_{1}} \sum_{m=n_{1}}^{n} \xi_{l, m, h}^{(k)}
$$

i.e. both (6) and (7) are normalised so as to lie in the $[0,1]$ interval.

In order to identify the direction of the linkages between the two (aggregate) blocs of countries, we define the regional net spillover index, $\gamma_{\text {net }, h}^{(k)}$, as the difference between growth spillovers from and to others in terms of the elements belonging to the external bloc of the system

$$
\gamma_{\text {net }, h}^{(k)}=\sum_{l=n_{1}+1}^{n} \sum_{m=1}^{n_{1}} \xi_{l, m, h}^{(k)}-\sum_{l=1}^{n_{1}} \sum_{m=n_{1}+1}^{n} \xi_{l, m, h}^{(k)}
$$

so that positive (negative) values for (8) indicate that the region is a net transmitter (receiver) to (from) outside (Diebold and Yilmaz 2012; Antonakakis and Badinger 2012). Using condition (8), it is straightforward to obtain a breakdown for the individual countries forming the external bloc, so that we can define $n-n_{1}$ pairwise regional net spillover indexes, $\gamma_{c t y, h}^{(k)}$, as

$$
\gamma_{c t y, h}^{(k)}=\sum_{m=1}^{n_{1}} \xi_{c t y, m, h}^{(k)}-\sum_{l=1}^{n_{1}} \xi_{c t y, m, h}^{(k)}
$$

where cty $=n_{1}+1, \ldots, n$.

Before discussing the empirical findings, it is worth noting that the $\gamma$ 's indices depend on the simulation span (through the index $h$ ) and on the estimation sample (through the index $k$ ). This is motivated by the need for a sufficiently flexible model specification to analyse the sources of business cycles in a period such as the recent one characterised by exceptionally large fluctuations. ${ }^{4}$ Further, considering a wide

\footnotetext{
4 Note that since the GFEVs are transformations of model parameters, allowing for time variation in the parameters of the underlying empirical model translates into time-varying nonlinear dynamic interactions among the elements in $y$ in (1).
} 
range of simulation horizons enables us to obtain a dynamic picture of how crosscountry business cycle linkages evolve when moving from the short to the long run through a sequence of GFEV decompositions for which the conditioning information is becoming progressively less important as the simulation horizon widens. ${ }^{5}$

\section{Assessing business cycle co-movements in the LA bloc}

\subsection{Data and preliminary analysis}

We use quarterly real GDP series for six major LA countries (namely, Argentina, Brazil, Chile, Mexico, Peru and Venezuela) and for the four largest economies in the world (the US, the Euro area, Japan and China) over the period 1980:I-2011:IV. ${ }^{6}$ The 10 chosen economies represent about $75 \%$ of real world GDP, with the six LA countries included representing approximately $85 \%$ of real GDP in the LA region over the period 1980-2010 according to the World Development Indicator data.

As a preliminary step, we test for the presence of unit roots in the GDP series in logarithms. ADF tests are performed, both on the levels and the first differences of the series. In each case, we are unable to reject the null hypothesis of a unit root in the levels at conventional significance levels. On the other hand, differencing the series appears to induce stationarity. Standard stationarity tests corroborate this conclusion. ${ }^{7}$

Given the nonstationarity of the time series and the lack of an economic theory suggesting the number of long-run relationships and/or how they should be interpreted, it is reasonable not to impose the restriction of cointegration on a VAR model (Ramaswamy and Sloek 1998). Thus, we have opted for a specification in first differences since the focus of our analysis is on (time-varying) short-run linkages rather than secular trends (as, for instance, in Bernard and Durlauf 1995).

We choose size 80 for the rolling windows (i.e. 20 years of quarterly observations, 80 observations in all). This can be regarded as a compromise between stability and flexibility, as it turned out that a smaller window size makes the VAR models more unstable. ${ }^{8}$ Such a choice implies that the complete set of recursions produces 48

\footnotetext{
5 Note that Diebold and Yilmaz (2012) focus on a selected forecast horizon rather than a continuum of simulation steps. Obtaining full information from the entire simulation horizon is therefore novel in this context.

6 The GDP series are taken from datastream and seasonally adjusted by using the X-12 method, as suggested by Cesa-Bianchi et al. (2011). Their codes are: AGXGDPR.C (Argentina), BRXGDPR.C (Brazil), CLI99BVPH (Chile), MXI99BVRG (Mexico), PEI99BVPH (Peru), VEXGDPR.C (Venezuela), USXGDPR.D (US), EKXGDPR.D (euro area), JPXGDPR.D (Japan) and CHXGDPR.C (China). Other economies of the LA region (such as Colombia or Bolivia) are not included in the analysis because of the lack of data on GDP for the eighties. The same choice was made by Boschi and Girardi (2011) and Caporale et al. (2011), among others.

7 These results are not reported to save space.

8 For each rolling estimate, the VAR models are specified with two lags. Experimenting with shorter and longer lag lengths (1 lag and 3 lags, respectively) did not change much the estimation results.
} 
different sets of VAR estimates. ${ }^{9}$ The GFEV decomposition analysis is then conducted over a simulation horizon of 20 quarters ( 5 years).

\subsection{Empirical evidence}

The variance decomposition for the LA region is computed as an (equally weighted) average of individual country-specific figures. ${ }^{10}$ According to Eqs. (6) and (7), it is based on a synthetic economy which is an "average" LA country, as in Izquierdo et al. (2008). Figure 1 shows the decomposition of the output variance into region-specific (Panel A) and external sources (Panel B).

Regarding the regional sources of fluctuations, their relative importance vis-à-vis the external ones appears to diminish over the simulation horizon. The dominant role of external factors in the long run is found for all quarters. In particular, external factors account for about $30 \%$ of the long-run (20-quarter horizon) variance of LA GDP growth, consistently with the evidence in Österholm and Zettelmeyer (2007) and in Aiolfi et al. (2010).

As for the evolution over time of the estimated effects, the relative contribution of the two types of factors is remarkably stable up to the first half of 2008. With the onset of the global crisis, external factors appear to acquire an increasing role, especially at the very bottom of the global downturn (between mid-2008 and mid2009), accounting for more than 50\% of total variability in 2008:IV. Subsequently, following a partial recovery, idiosyncratic factors have regained some (but not all) of their former importance. Our findings therefore give support to previous evidence according to which the LA region is still characterised by heavy dependence on external factors and does not carry sufficient weight to affect the international business cycle with its own growth dynamics (Calvo et al. 1993; Izquierdo, 2008; Cesa-Bianchi et al. 2011), thus contradicting the so-called decoupling hypothesis (Helbling et al. 2007).

Further evidence is presented in Fig. 2, which shows the difference between growth spillovers to and from the external bloc of the system as defined by (8). There is a predominance of negative values for the rolling estimates (especially when considering long-run effects), suggesting that the LA region can be characterised as a net receiver. This applies even more strongly to the recovery period after the peak of the global crisis: The long-run net effect, after reaching a minimum of $-17 \%$ in 2008:IV, is about $-8 \%$ at the end of the sample.

However, net spillover effects vis-à-vis an aggregate "rest of the world" could hide underlying heterogeneity, which can only be detected by a more disaggregate analysis. Figure 3 presents the net pairwise spillover effects between the LA region and the US (Panel A), the Euro area (Panel B), Japan (Panel C) and China (Panel D).

\footnotetext{
9 More specifically, the first estimation uses observations from 1980:I to 1999:IV, the second from 1980:II to 2000:I, and so on, the last being based on the period from 1992:I to 2011:IV.

10 The "Appendix" explains how to obtain metrics in order to disentangle the sources of business cycle fluctuations at the level of the individual countries forming the LA bloc. We document a high degree of heterogeneity among them: Argentina, Mexico and Peru appear to be increasingly dependent on external developments as a result of the great recession, whilst Venezuela seems to be influenced mainly by the LA regional business cycle. Only in the case of Brazil, a decreasing role of the external factors is found.
} 
Panel A - Region-specific component

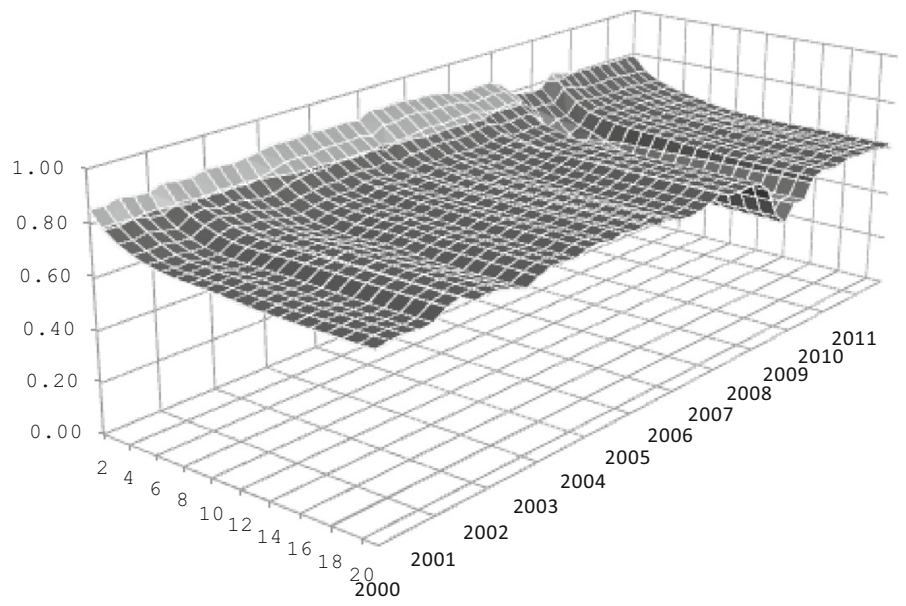

Panel B - External component

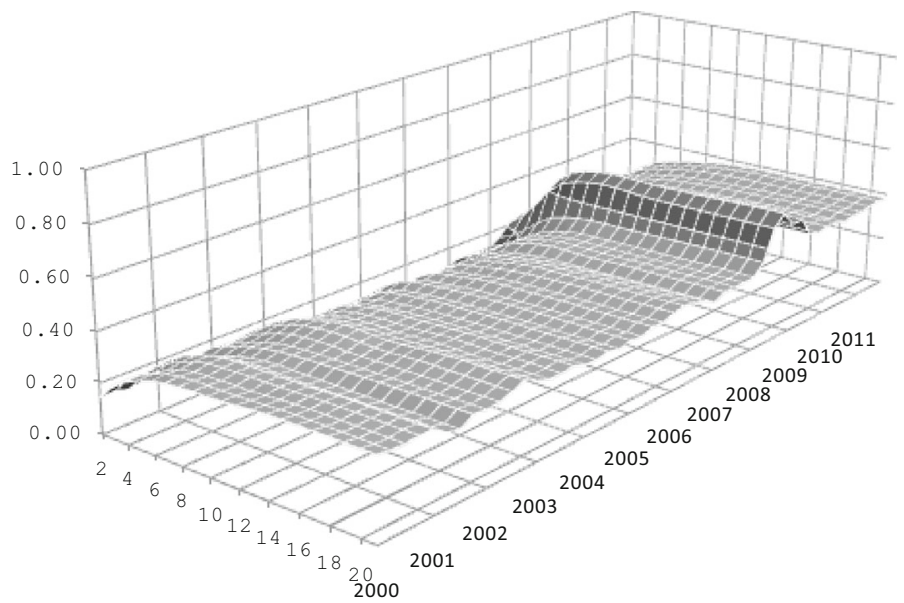

Fig. 1 LA region: region-specific versus external factors. Note In each tri-dimensional graph, the horizontal plane is spanned by the temporal horizon and the simulation steps, whilst the vertical axis measures the intensity of the indicators given by conditions (6) and (7)

Both short- and long-run effects appear to be very stable, especially in the case of China. In particular, the balance between growth spillovers to and from the outside world is negative for the LA region in most cases. This is largely true for the years of the great recession (2007-2009), during which the LA region suffered from the recessionary impulses coming from the most advanced economies (but not from China). In the most recent years, however, the overall picture seems to have changed significantly, namely the impact of business cycle conditions in the US, the Euro area and Japan has diminished, whilst the influence of the Chinese economy has increased. 


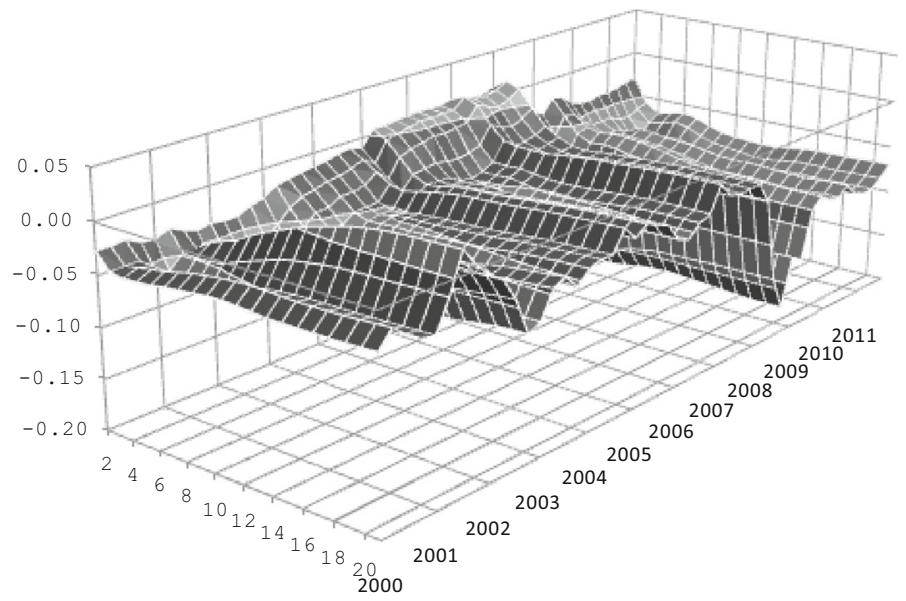

Fig. 2 LA region: net effects (region-specific minus external factors). Note In each tri-dimensional graph, the horizontal plane is spanned by the temporal horizon and the simulation steps, whilst the vertical axis measures the intensity of the indicator as defined by condition (8). Positive (negative) values indicate that growth spillovers to external countries are greater (lower) than those from them
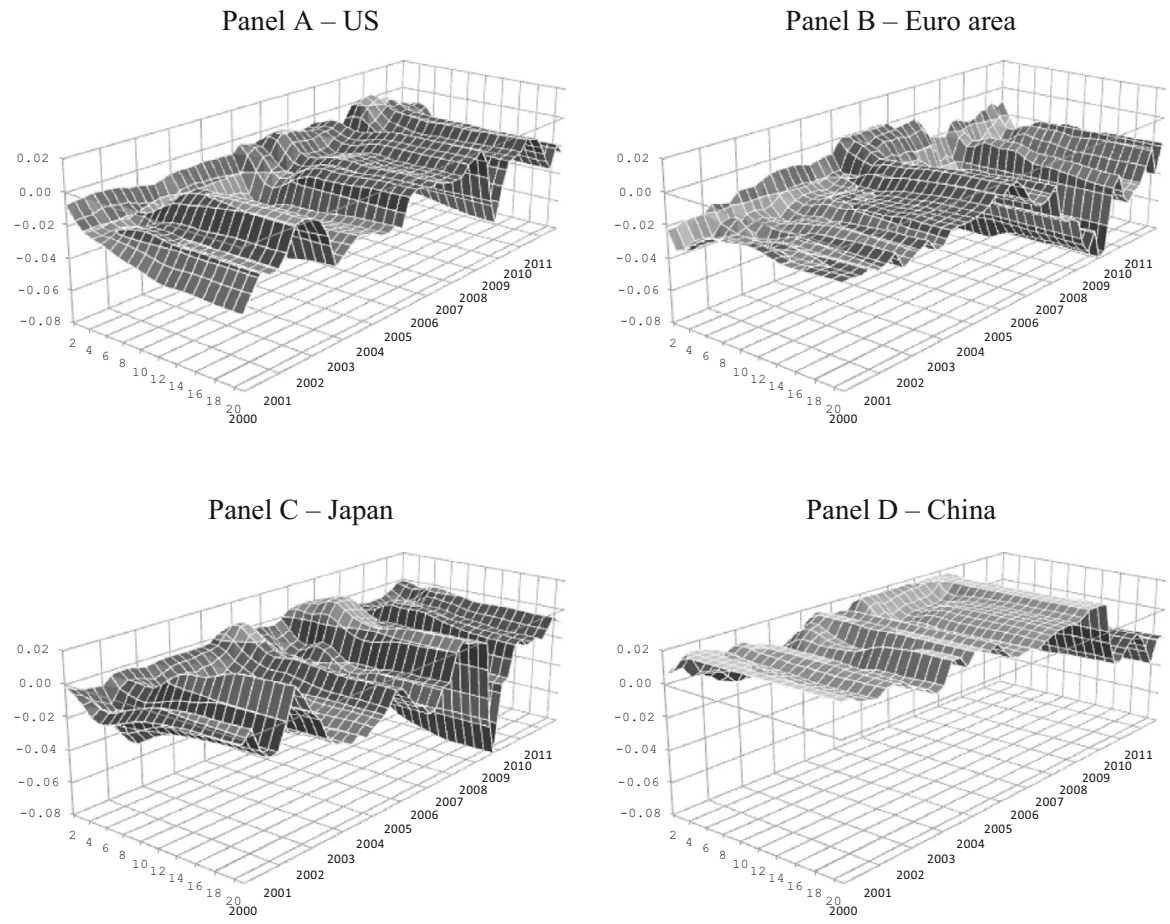

Fig. 3 LA region: net effects (region-specific minus individual foreign country factors). Note In each tridimensional graph, the horizontal plane is spanned by the temporal horizon and the simulation steps, whilst the vertical axis measures the intensity of the indicator given by condition (9) 
Overall, the disaggregate results provide no evidence of de-coupling; they also indicate that bilateral linkages with China have become stronger, making the LA region vulnerable not only to economic hardship in the industrialised economies but also to future developments in China, as already pointed out by Cesa-Bianchi et al. (2011).

\section{Determinants of the linkages between the LA region and the world economy}

\subsection{The role of trade and capital flows}

Since the study of Frankel and Rose (1998) a considerable body of empirical research (Kalemli-Ozcan et al. 2009; Imbs 2010; Caporale et al. 2014) has shown that bilateral trade flows ( $\mathrm{tr}$ ) and financial linkages $(\mathrm{fin})$ can affect business cycles correlations $(\rho)$ across countries and/or regions, following this literature, a canonical regression model can be specified as

$$
\rho=\psi_{1}+\psi_{2} \operatorname{tra}+\psi_{3} f i n+\varepsilon
$$

The positive effect of bilateral trade flows on the degree of international business cycle synchronisation has been widely established in that literature and is consistent with the theoretical predictions of the model developed by Kose and Yi (2006). As for capital flows, several studies give support to the view that financial integration increases the degree of business cycle correlations in cross sections and over time (Imbs 2010), whilst other papers (e.g. Kalemli-Ozcan et al. 2009) find that financially integrated economies have negative co-movements, as posited by standard international real business cycle models with complete markets (Backus et al. 1994). The sign for $\psi_{3}$ in (13) is thus the object of empirical scrutiny. ${ }^{11}$

We follow Frankel and Rose (1998) and compute (a time variant version of) bilateral trade intensities as

$$
t r a_{t}=\frac{X_{l, e, t}+X_{e, l, t}}{Y_{l, t}+Y_{e, t}}
$$

where $X_{l, e, t}$ denote total merchandise exports from the LA region $(l)$ to the external bloc $(e), X_{e, l, t}$ are exports from the aggregate foreign economy to the LA region, $Y_{l, t}$ and $Y_{e, t}$ are the GDP nominal levels in the two economies, and $t$ is a time index.

As for capital flows between the two blocs, these are proxied as

$$
f i n_{t}=\left|\frac{\mathrm{NFA}_{l, t}}{Y_{l, t}}-\frac{\mathrm{NFA}_{e, t}}{Y_{e, t}}\right|
$$

\footnotetext{
11 In the literature additional explanatory variables for $\rho$, such as exchange rate arrangements and the structure of production and trade have been suggested. However, we are interested in explaining how the degree of business cycle synchronisation has changed over time rather than across countries, and therefore, time-invariant regressors or explanatory variables that only change slowly over time are ruled out from the present study. A time series analysis of the determinants of business cycle correlations is quite novel, only a limited number of studies on this topic being available at present (see, among others, Kalemli-Ozcan et al. 2009; Imbs 2010).
} 
where $\mathrm{NFA}_{l, t}$ and $\mathrm{NFA}_{e, t}$ stand for the (multilateral) net foreign asset position in the two aggregate economies. The rationale for this proxy is that capital should flow between countries or regions with different external positions: bilateral flows between two countries with the same net position should be less than between countries with opposite positions (Imbs (2003)). In particular, we compute the net foreign asset position as the sum of net positions in debt $(d b t)$, equities (eqt) and foreign direct investment $(f d i){ }^{12}$

\subsection{Estimation results}

Using spillover indexes rather than standard correlation coefficients makes it possible to analyse (time-varying) business cycle correlations in a much more flexible framework by distinguishing between co-movements at different forecast horizons. To see this, we start by mapping our spillover index to the (time-varying) correlation coefficients. Following Forbes and Rigobon (2002), we consider the following least square regression between output growth rates of countries $a$ and $b, \Delta y_{a}=a+b \Delta y_{b}+u$, so that

$$
\rho=\left[\frac{b^{2} \sigma_{b}^{2}}{\sigma_{a}^{2}}\right]^{0.5} \quad \text { or } \quad \frac{\rho}{b}=\left[\frac{\sigma_{b}^{2}}{\sigma_{a}^{2}}\right]^{0.5}
$$

The term in square brackets on the RHS of the second expression in (11) is the share of output growth variability of country $a$ explained by $b$. In terms of our framework, it is expressed by $\gamma_{\text {ext }}$ in (10). Condition (11) implies that $\rho^{*}=\rho / b=\sqrt{\gamma_{\mathrm{ext}}}$ (for a given forecast horizon). Accordingly, Eq. (10) can be rewritten as follows

$$
\rho_{h}^{*}=\alpha_{1}^{*}+\alpha_{2}^{*} \operatorname{tra}+\alpha_{3}^{*} f i n+\varepsilon^{*}
$$

where $\alpha_{i}^{*}=\alpha_{i} / b, i=1, \ldots, 3, \varepsilon=\varepsilon / b$ provided that $b \neq 0$. As $\gamma_{\text {ext }}$ is computed over a number of different simulation steps, $h$, condition (12) can be tested at several forecast horizons in order to assess whether and how the role of trade and financial linkages varies according to $h$. In what follows, we consider selected simulation horizons (namely, $h=1,2,4,8,12,20$ ).

The first step of the empirical analysis is based on standard correlation measures between $\rho^{*}$ and its main macroeconomic determinants. Table 1 shows that the unconditional correlation coefficients for the $\rho^{*}$ 's and $\operatorname{tr} a$ variables are positive and statistically significant for all forecast horizons considered, confirming the well-established finding that higher business cycle synchronisation is associated with stronger trade intensity. One might argue that the positive correlation is spurious owing to the existence of factors correlated to both variables. When conditioning on fin, the magnitude

\footnotetext{
12 Bilateral trade data and statistics for capital flows are from the IMF's DoTS and IFS BoP databases, respectively. The analysis focuses on net capital flows. Since IFS BoP records outflows as negative numbers, to obtain net flows assets and liabilities are added. FDI data for China are not available for the entire sample span considered in the analysis, and therefore, $f d i$ is computed using data only for the US, the Euro area and Japan. The series have been seasonally adjusted using the X-12 method.
} 
Table 1 Correlation analysis: business cycle co-movements vs trade and capital flows

\begin{tabular}{|c|c|c|c|c|c|c|}
\hline & $h=1$ & $h=2$ & $h=4$ & $h=8$ & $h=12$ & $h=20$ \\
\hline \multicolumn{7}{|c|}{ Unconditional correlations } \\
\hline $\operatorname{corr}\left(\rho_{h}^{*}, \operatorname{tra}\right)$ & $\begin{array}{l}0.424 * * * \\
(0.005)\end{array}$ & $\begin{array}{l}0.486^{* * * *} \\
(0.001)\end{array}$ & $\begin{array}{l}0.550 * * * \\
(0.000)\end{array}$ & $\begin{array}{l}0.538 * * * \\
(0.000)\end{array}$ & $\begin{array}{l}0.497 * * * \\
(0.001)\end{array}$ & $\begin{array}{l}0.507 * * * \\
(0.001)\end{array}$ \\
\hline $\operatorname{corr}\left(\rho_{h}^{*}, f i n\right)$ & $\begin{array}{r}0.119 \\
(0.447\end{array}$ & $\begin{array}{c}0.140 \\
(0.370)\end{array}$ & $\begin{array}{c}0.199 \\
(0.202)\end{array}$ & $\begin{array}{c}0.122 \\
(0.435)\end{array}$ & $\begin{array}{c}0.096 \\
(0.540)\end{array}$ & $\begin{array}{c}0.034 \\
(0.831)\end{array}$ \\
\hline \multicolumn{7}{|c|}{ Conditional correlations } \\
\hline $\operatorname{corr}\left(\rho_{h}^{*}, \operatorname{tra} \mid\right.$ fin $)$ & $\begin{array}{l}0.410 * * * \\
(0.007)\end{array}$ & $\begin{array}{l}0.470 * * * \\
(0.002)\end{array}$ & $\begin{array}{l}0.524 * * * \\
(0.000)\end{array}$ & $\begin{array}{l}0.530^{* * * *} \\
(0.000)\end{array}$ & $\begin{array}{l}0.493 * * * \\
(0.001)\end{array}$ & $\begin{array}{l}0.521 * * * \\
(0.000)\end{array}$ \\
\hline $\operatorname{corr}\left(\rho_{h}^{*}\right.$, fin $\mid$ tra $)$ & $\begin{array}{r}-0.010 \\
(0.949)\end{array}$ & $\begin{array}{r}-0.007 \\
(0.963)\end{array}$ & $\begin{array}{c}0.041 \\
(0.796)\end{array}$ & $\begin{array}{r}-0.050 \\
(0.753)\end{array}$ & $\begin{array}{r}-0.065 \\
(0.682)\end{array}$ & $\begin{array}{r}-0.145 \\
(0.359)\end{array}$ \\
\hline
\end{tabular}

Bilateral trade intensities (tra) and capital flows (fin) are defined in Sect. 4.1. $h$ indicates the forecast horizon (in quarters). $* * *$ denote statistically significant coefficients at the $1 \%$ level. $p$ values are reported in parentheses

(and the statistical significance) of the partial correlation coefficients remains virtually unchanged. By contrast, the unconditional correlation between $\rho^{*}$ 's and fin turn out to be statistically insignificant. The same conclusion holds when considering the partial measure of association (conditioned on tra), even though the sign of the relationship in general becomes negative.

Correlations are only partially informative as they cannot gauge causality between the regressand and the explanatory covariates. In order to delve deeper into the effects of bilateral trade and capital flows on business cycle synchronisation, we estimate Eq. (12) by 2 SLS for the chosen simulation horizons. ${ }^{13}$ In order to control for the collapse (and the subsequent abrupt recovery) in trade flows which occurred during the 2008-2009 crisis, we augment the set of regressors by a crisis dummy (dum) taking the value of -1 in 2008:III and 2008:IV and +1 in 2009:I and 2009:II. ${ }^{14}$

Table 2 presents the estimation results of the baseline specification. ${ }^{15}$ Single, double or triple asterisks denote statistically significant coefficients at the 1,5 or $10 \%$ level, respectively. We also report robust standard errors (in parentheses) as well as some basic diagnostics for the chosen instruments ( $J$ statistics), the serial correlation of the residuals $(D W)$ and the goodness of fit of the regression $\left(R_{\text {adj }}^{2}\right)$.

The estimation results indicate a clear dominance of trade flows over financial linkages as the main determinant of business cycle co-movements between the LA

\footnotetext{
13 Typical external instruments for trade intensity are spatial characteristics (e.g. geographical proximity or the presence of common borders) and for financial integration institutional variables related to legal arrangements. As most of these instruments are constant over time, they cannot be used in a time series framework. In order to address endogeneity concerns, bilateral trade intensity and capital flows are measured at the beginning of the period and are treated as pre-determined variables.

14 The crisis dummy has been introduced without any formal testing procedure, as also in Contessi et al. (2014), for example, In any case, the estimation results in Sects. 4.2 and 4.3. are not affected by the inclusion of dum: re-estimating model (12) without it produces qualitatively similar results to those reported in the main text.

15 After considerable experimentation, our preferred specification is based on variables expressed in yearon-year changes. For the purpose of readability, variables have been standardised.
} 
Table 2 Business cycle co-movements, trade intensity and aggregate capital flows

\begin{tabular}{lcccccc}
\hline & $h=1$ & $h=2$ & $h=4$ & $h=8$ & $h=12$ & $h=20$ \\
\hline tra & $0.224 * * *$ & $0.267 * * *$ & $0.328 * * *$ & $0.328 * * *$ & $0.297 * * *$ & $0.321 * * *$ \\
& $(0.077)$ & $(0.084)$ & $(0.125)$ & $(0.073)$ & $(0.103)$ & $(0.072)$ \\
fin & -0.028 & -0.027 & 0.017 & -0.065 & -0.079 & -0.152 \\
& $(0.095)$ & $(0.07)$ & $(0.154)$ & $(0.149)$ & $(0.159)$ & $(0.118)$ \\
dum & $1.680 * * *$ & $1.834 * *$ & $1.801 * * *$ & $1.909 * * *$ & $1.847 * * *$ & $1.917 * * *$ \\
& $(0.179)$ & $(0.126)$ & $(0.230)$ & $(0.123)$ & $(0.162)$ & $(0.104)$ \\
$J$ & 0.86 & 0.44 & 0.96 & 0.30 & 0.41 & 0.36 \\
$D W$ & 2.31 & 2.35 & 2.10 & 1.92 & 2.29 & 2.20 \\
$R_{\text {adj }}^{2}$ & 0.35 & 0.46 & 0.52 & 0.54 & 0.47 & 0.52 \\
\hline
\end{tabular}

The dependent variable is the measure of business cycle co-movement computed according to condition (15) of the main text for selected simulation horizons. Bilateral trade intensities (tra) and capital flows (fin) are defined in Sect. 4.1. The crisis dummy (dum) takes the value of -1 in 2008:III and 2008:IV and -1 in 2009:I and 2009:II. h indicates the forecast horizon (in quarters). The last three rows report some basic diagnostics for the chosen instruments ( $J$ statistics), the serial correlation of the residuals $(D W)$ and the goodness of fit of the regression $\left(R_{\mathrm{adj}}^{2}\right)$. * ** or *** denote statistically significant coefficients at the 1, 5 or $10 \%$ level, respectively. Robust standard errors are reported in parentheses

region and the foreign bloc, even controlling for the trade collapse in 2008-2009: The coefficient of bilateral trade intensity is positive and statistically significant at all simulation steps; moreover, it increases almost monotonically with $h$. Capital flows reduce the degree of co-movement between cycles, but the coefficients of $f$ in are generally small in magnitude and imprecisely estimated.

Overall, these findings show that in the presence of relatively weak financial linkages, propagation of the impulses from outside to the LA bloc has taken place mainly through trade flows. The apparent de-coupling of the LA bloc from the most advanced economies thus arises not only from trade being increasingly oriented towards China rather than its historical trading partners (namely the US and the Euro area-see CesaBianchi et al. (2011) but also from a low degree of financial integration with the rest of the world economy.

\subsection{Extensions}

In this Section, we present the results from a disaggregate analysis based on a breakdown of capital flows into debt, equity and FDI flows with the aim of shedding light on what type of flows are behind stronger business cycle co-movements.

We first assess the role of these components by replacing $f i n$ with disaggregated capital flows (entering the model individually). The results in Table 3 indicate that the trade channel, albeit dominant, is not the only one: Capital flows can also affect the degree of international business cycle synchronisation in the short run (namely, up to the fourth simulation step). Moreover, portfolio equity flows have a negative effect on the degree of business cycle synchronisation whilst that of debt and foreign direct investment is positive.

As a further step, we consider a specification where the three types of flows enter the model simultaneously (Table 4). Over the first year of the simulation horizon, its explanatory power is higher with respect to its (nested) counterparts in Tables 2 and 3 , 
Table 3 Business cycle co-movements, trade intensity and sub-components of capital flows

\begin{tabular}{|c|c|c|c|c|c|c|}
\hline & $h=1$ & $h=2$ & $h=4$ & $h=8$ & $h=12$ & $h=20$ \\
\hline \multicolumn{7}{|c|}{ Debt flows } \\
\hline tra & $\begin{array}{l}0.137 * * \\
(0.062)\end{array}$ & $\begin{array}{l}0.224 * * \\
(0.104)\end{array}$ & $\begin{array}{l}0.286^{* * *} \\
(0.114)\end{array}$ & $\begin{array}{l}0.293 * * * \\
(0.064)\end{array}$ & $\begin{array}{l}0.268 * * * \\
(0.097)\end{array}$ & $\begin{array}{l}0.257 \text { *** } \\
(0.063)\end{array}$ \\
\hline$d b t$ & $\begin{array}{l}0.257 * * \\
(0.098)\end{array}$ & $\begin{array}{c}0.116 \\
(0.113)\end{array}$ & $\begin{array}{c}0.152 \\
(0.093)\end{array}$ & $\begin{array}{c}0.051 \\
(0.074)\end{array}$ & $\begin{array}{c}0.020 \\
(0.096)\end{array}$ & $\begin{array}{c}0.061 \\
(0.152)\end{array}$ \\
\hline$d u m$ & $\begin{array}{l}1.557 * * * \\
(0.146)\end{array}$ & $\begin{array}{l}1.777 * * * \\
(0.125)\end{array}$ & $\begin{array}{l}1.732 * * * \\
(0.272)\end{array}$ & $\begin{array}{l}1.877 * * * \\
(0.142)\end{array}$ & $\begin{array}{l}1.828 * * * \\
(0.165)\end{array}$ & $\begin{array}{l}1.869 * * * \\
(0.095)\end{array}$ \\
\hline$J$ & 0.90 & 0.38 & 0.76 & 0.35 & 0.38 & 0.30 \\
\hline$D W$ & 2.24 & 2.37 & 2.18 & 1.97 & 2.34 & 2.32 \\
\hline$R_{\text {adj }}^{2}$ & 0.40 & 0.47 & 0.53 & 0.54 & 0.47 & 0.50 \\
\hline \multicolumn{7}{|c|}{ Equity flows } \\
\hline tra & $\begin{array}{l}0.322 * * \\
(0.139)\end{array}$ & $\begin{array}{l}0.344 * * * \\
(0.088)\end{array}$ & $\begin{array}{l}0.427 * * * \\
(0.124)\end{array}$ & $\begin{array}{l}0.386^{* * * *} \\
(0.089)\end{array}$ & $\begin{array}{l}0.317 * * * \\
(0.093)\end{array}$ & $\begin{array}{l}0.324 * * * \\
(0.046)\end{array}$ \\
\hline eqt & $\begin{array}{c}-0.262 * * \\
(0.118)\end{array}$ & $\begin{array}{c}-0.210 * * \\
(0.08)\end{array}$ & $\begin{array}{c}-0.232 * * * \\
(0.081)\end{array}$ & $\begin{array}{c}-0.192 * * \\
(0.082)\end{array}$ & $\begin{array}{r}-0.108 \\
(0.080)\end{array}$ & $\begin{array}{r}-0.118 \\
(0.076)\end{array}$ \\
\hline$d u m$ & $\begin{array}{l}1.663 * * * \\
(0.309)\end{array}$ & $\begin{array}{l}1.820 * * * \\
(0.135)\end{array}$ & $\begin{array}{l}1.791 * * * \\
(0.217)\end{array}$ & $\begin{array}{l}1.891 * * * \\
(0.105)\end{array}$ & $\begin{array}{l}1.832 * * * \\
(0.178)\end{array}$ & $\begin{array}{l}1.892 * * * \\
(0.086)\end{array}$ \\
\hline$J$ & 0.52 & 0.23 & 0.51 & 0.55 & 0.31 & 0.30 \\
\hline$D W$ & 2.41 & 2.40 & 2.09 & 2.00 & 2.34 & 2.30 \\
\hline$R_{\text {adj }}^{2}$ & 0.42 & 0.50 & 0.57 & 0.57 & 0.48 & 0.51 \\
\hline \multicolumn{7}{|c|}{ Foreign direct investment flows } \\
\hline tra & $\begin{array}{l}0.195 * * \\
(0.083)\end{array}$ & $\begin{array}{l}0.237 * * \\
(0.099)\end{array}$ & $\begin{array}{l}0.321 * * \\
(0.127)\end{array}$ & $\begin{array}{l}0.302 * * * \\
(0.076)\end{array}$ & $\begin{array}{l}0.273 * * * \\
(0.077)\end{array}$ & $\begin{array}{l}0.282 * * * \\
(0.057)\end{array}$ \\
\hline$f d i$ & $\begin{array}{c}0.154 \\
(0.106)\end{array}$ & $\begin{array}{l}0.158 * * \\
(0.061)\end{array}$ & $\begin{array}{c}0.081 \\
(0.106)\end{array}$ & $\begin{array}{c}0.049 \\
(0.129)\end{array}$ & $\begin{array}{c}0.008 \\
(0.123)\end{array}$ & $\begin{array}{r}-0.047 \\
(0.148)\end{array}$ \\
\hline$d u m$ & $\begin{array}{l}1.657 * * * \\
(0.201)\end{array}$ & $\begin{array}{l}1.811 * * * \\
(0.164)\end{array}$ & $\begin{array}{l}1.792 * * * \\
(0.257)\end{array}$ & $\begin{array}{l}1.895 * * * \\
(0.118)\end{array}$ & $\begin{array}{l}1.836 * * * \\
(0.143)\end{array}$ & $\begin{array}{l}1.904 * * * \\
(0.093)\end{array}$ \\
\hline$J$ & 0.99 & 0.57 & 0.98 & 0.31 & 0.42 & 0.35 \\
\hline$D W$ & 2.23 & 2.30 & 2.12 & 1.94 & 2.32 & 2.26 \\
\hline$R_{\text {adj }}^{2}$ & 0.38 & 0.48 & 0.52 & 0.54 & 0.47 & 0.50 \\
\hline
\end{tabular}

The dependent variable is the measure of business cycle co-movement computed according to condition (15) of the main text for selected simulation horizons. Bilateral trade intensities (tra) and the decomposition of the net foreign asset position into debt $(d b t)$, equities $(e q t)$ and foreign direct investment $(f d i)$ components are defined in Sect. 4.1. The crisis dummy (dum) takes the value of -1 in 2008:III and 2008:IV and -1 in 2009:I and 2009:II. $h$ indicates the forecast horizon (in quarters). The last three rows report some basic diagnostics for the chosen instruments ( $J$ statistics), the serial correlation of the residuals $(D W)$ and the goodness of fit of the regression $\left(R_{\mathrm{adj}}^{2}\right)$. *** or $* * *$ denote statistically significant coefficients at the 1,5 or $10 \%$ level, respectively. Robust standard errors are reported in parentheses

suggesting that debt, portfolio equity and foreign direct investment act as additional channels of transmission of shocks from abroad.

Our findings complement previous evidence for emerging markets according to which both trade and financial variables mattered prior to the global crisis (Blanchard et al. 2010), since we document that these factors largely explain business cycle comovements over the last decade. However, our framework makes it possible to go further and to highlight the relative strength of the different transmission channels in the short and long run: The increasing explanatory power of trade flows over the entire simulation span is largely corroborated, whereas capital flows affect business cycle 
Table 4 Business cycle co-movements, trade intensity and disaggregate capital flows

\begin{tabular}{lcccccc}
\hline & $h=1$ & $h=2$ & $h=4$ & $h=8$ & $h=12$ & $h=20$ \\
\hline tra & $0.239 * *$ & $0.301 * *$ & $0.376^{* * *}$ & $0.366^{* * *}$ & $0.309 * *$ & $0.306^{* * *}$ \\
& $(0.102)$ & $(0.137)$ & $(0.096)$ & $(0.098)$ & $(0.135)$ & $(0.049)$ \\
$d b t$ & $0.248^{* * *}$ & 0.095 & 0.155 & 0.054 & 0.026 & 0.083 \\
& $(0.085)$ & $(0.116)$ & $(0.098)$ & $(0.077)$ & $(0.107)$ & $(0.100)$ \\
$e q t$ & $-0.287 *$ & $-0.227 * *$ & $-0.246 * *$ & $-0.197^{*}$ & $-0.110^{*}$ & $-0.120^{* *}$ \\
& $(0.156)$ & $(0.087)$ & $(0.119)$ & $(0.114)$ & $(0.062)$ & $(0.050)$ \\
$f d i$ & 0.128 & $0.155^{* *}$ & 0.069 & 0.051 & 0.009 & -0.055 \\
& $(0.107)$ & $(0.066)$ & $(0.108)$ & $(0.108)$ & $(0.120)$ & $(0.124)$ \\
$d u m$ & $1.531^{* * *}$ & $1.756^{* * *}$ & $1.710^{* * *}$ & $1.860 * * *$ & $1.818 * * *$ & $1.860^{* * *}$ \\
& $(0.168)$ & $(0.144)$ & $(0.181)$ & $(0.137)$ & $(0.146)$ & $(0.083)$ \\
$J$ & 0.59 & 0.25 & 0.36 & 0.63 & 0.27 & 0.23 \\
$D W$ & 2.31 & 2.40 & 2.19 & 2.07 & 2.36 & 2.33 \\
$R_{\text {adj }}^{2}$ & 0.46 & 0.51 & 0.57 & 0.55 & 0.45 & 0.49 \\
\hline
\end{tabular}

The dependent variable is the measure of business cycle co-movement computed according to condition (15) of the main text for selected simulation horizons. Bilateral trade intensities (tra) and the decomposition of the net foreign asset position into debt $(d b t)$, equities (eqt) and foreign direct investment (fdi) components are defined in Sect. 4.1. The crisis dummy (dum) takes the value of -1 in 2008:III and 2008:IV and -1 in 2009:I and 2009:II. $h$ indicates the forecast horizon (in quarters). The last three rows report some basic diagnostics for the chosen instruments ( $J$ statistics), the serial correlation of the residuals $(D W)$ and the goodness of fit of the regression $\left(R_{\mathrm{adj}}^{2}\right)$. * ** or *** denote statistically significant coefficients at the 1,5 or $10 \%$ level, respectively. Robust standard errors are reported in parentheses

co-movement in the short-term, as the $R_{\text {adj }}^{2}$ statistics show. ${ }^{16}$ Moreover, in the very short-term debt and foreign direct investment have an opposite effect compared to equity portfolio flows. Whilst the result for eqt can be rationalised within the standard international real business cycle framework with complete markets, our findings for $d b t$ and $f d i$ suggest that short-term capital flows and internationalisation of production through foreign direct investment may strengthen the role of trade channel making the LA region more prone to suffer from the propagation of shocks from abroad.

\section{Conclusions}

This paper uses the econometric approach of Diebold and Yilmaz (2012) to analyse the extent to which business cycle developments in the LA region and the four largest economies in the world (the US, the Euro area, Japan and China) were connected over the period 1980:I-2011:IV.

We document that the LA region as a whole is strongly dependent on external developments. This conclusion holds, especially for the years after the great recession of 2008 and 2009, ruling out any decoupling of the LA region from the rest of the world. More specifically, we find a clear dominance of trade flows over financial linkages as a determinant of business cycle co-movements between the LA region and the foreign bloc. The apparent de-coupling of the LA area with respect to the most

\footnotetext{
16 This also implies that the statistically significance of the coefficient on equity portfolio flows after the first four quarters of the simulation span makes only a marginal contribution to explaining how the LA bloc and the rest of the world co-move.
} 
advanced economies in recent years thus seems to have been determined not only by increasing trade flows towards China but also by a low degree of financial integration with its main economic partners.

The decomposition of capital flows into their components (debt, portfolio equity and foreign direct investment flows) shows a negative effect of portfolio equity flows on the degree of business cycle synchronisation, consistently with the predictions of standard international real business cycle models with complete markets. In contrast, short-term capital and foreign direct investment flows tend to reinforce in the short run the role of the trade channel and the responsiveness of the LA region to external developments.

Open Access This article is distributed under the terms of the Creative Commons Attribution License which permits any use, distribution, and reproduction in any medium, provided the original author(s) and the source are credited.

\section{Appendix: Evidence from LA individual countries}

Condition (5) in Sect. 2.3 makes it possible to quantify the contribution of countryspecific, $\delta_{c s, h}^{(k)}$, regional, $\delta_{r s, h}^{(k)}$ and external factors, $\delta_{e s, h}^{(k)}$, to explaining business cycle developments at the level of the individual countries forming the LA bloc. The three geographical sources of output fluctuations are defined as:

$$
\begin{aligned}
& \delta_{c s, h}^{(k)}=\xi_{l, l, h}^{(k)} \\
& \delta_{r s, h}^{(k)}=\sum_{m=1}^{n_{1}} \xi_{l, m, h}^{(k)}-\xi_{l, l, h}^{(k)} \\
& \delta_{e s, h}^{(k)}=\sum_{m=n_{1}+1}^{n} \xi_{l, m, h}^{(k)}
\end{aligned}
$$

for all $l=1, \ldots, n_{1}$.

Figure 4 shows the results obtained from this decomposition graphically. Regarding the country-specific components (graph I in Panels A-F), the proposed approach captures the deep crisis hitting Argentina at the beginning of the current decade, as shown by the sharp increase in the contribution of the country-specific component between the second half of 2011 and the first semester of 2012. Furthermore, the global downturn led to a sharp drop in the contribution of internal factors in the last part of 2008. By contrast, the relative contribution of country-specific factors was more stable over time for the remaining LA economies.

Concerning regional factors (graph II in Panels A-F), there is evidence of a sizeable regional business cycle component in the LA countries, as also found by Aiolfi et al. (2010) and Boschi and Girardi (2011), among others. Averaging over all simulation steps and rolling estimates, regional factors account from about 20 (in the case of Chile) to 40 per cent (for Venezuela) of output growth variability.

Finally, the average effect of external factors (graph III in Panels A-F) is within a similar range to the one for the regional components (as also in Aiolfi et al. 2010), 

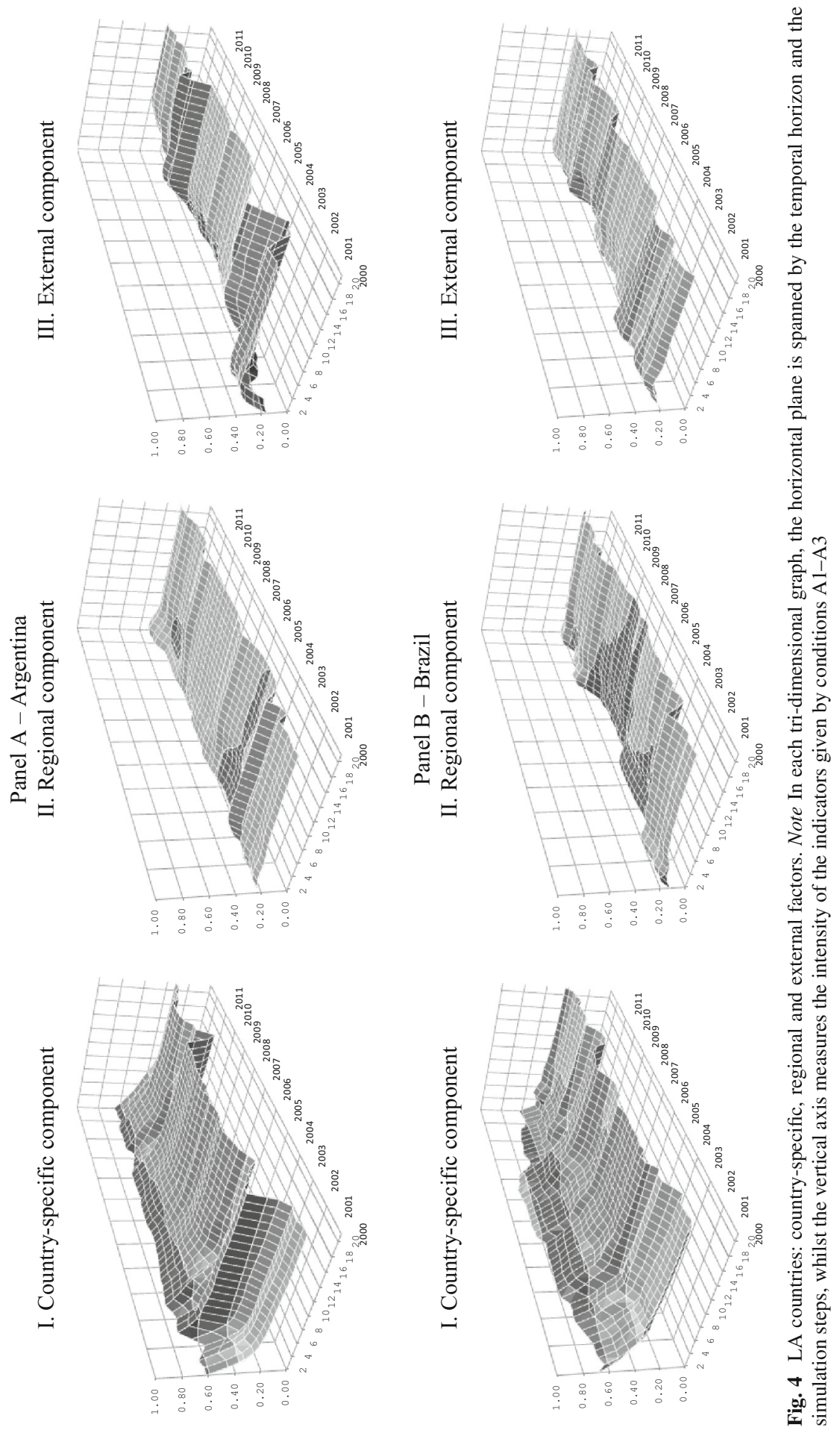

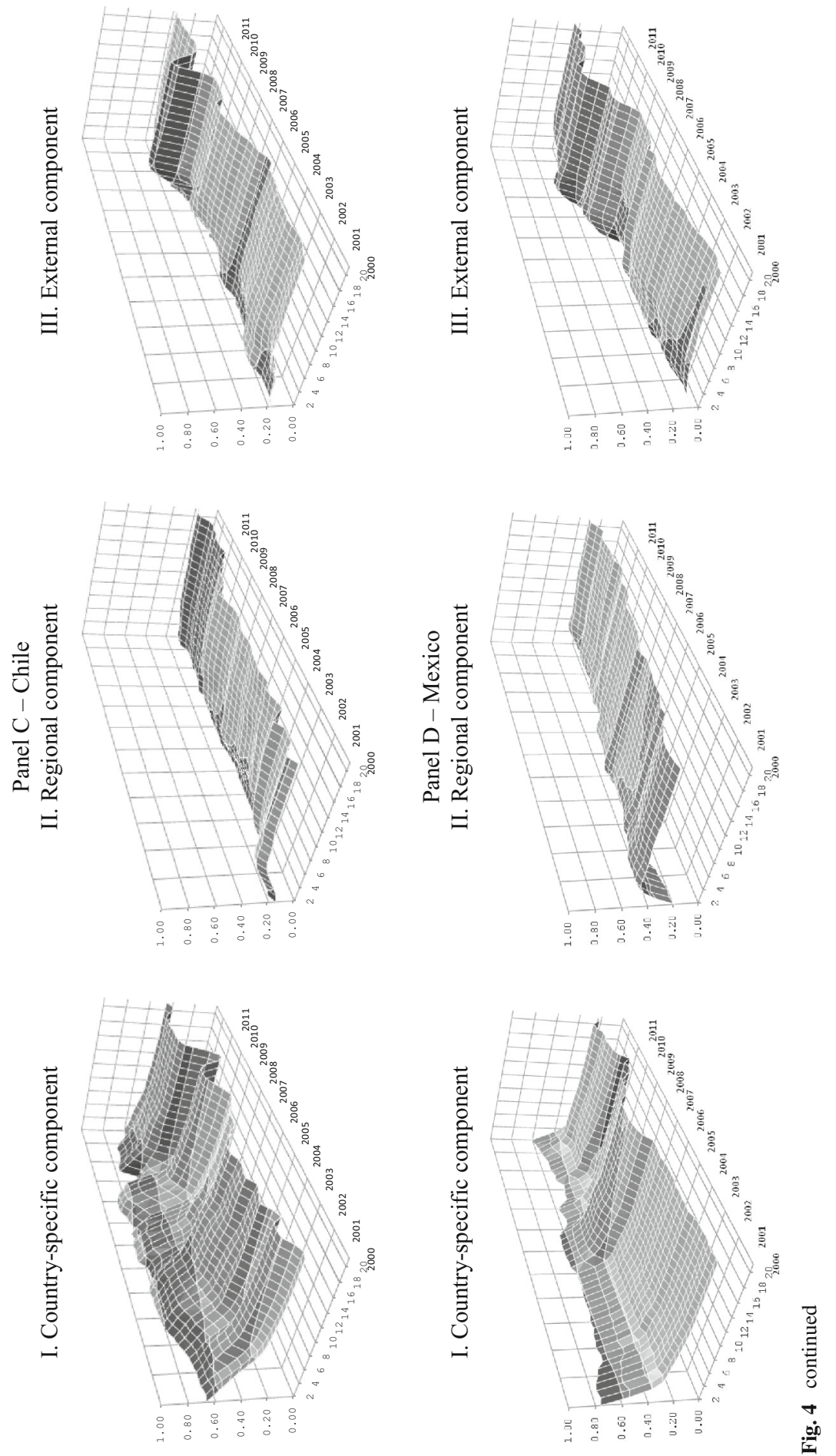

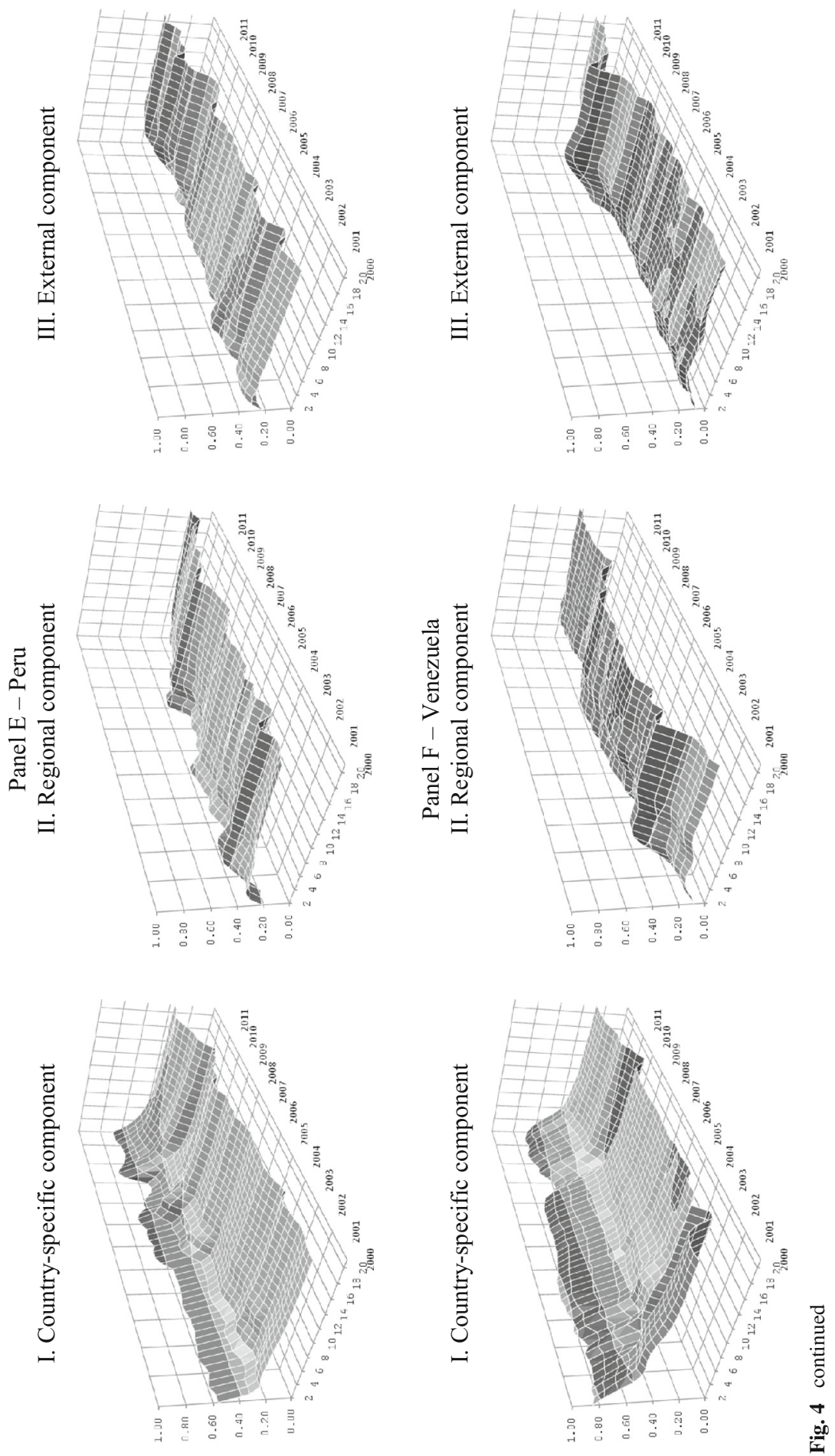
its minimum and maximum values being those for Venezuela and Peru, respectively. As for the individual countries, the observed pattern for Argentina mirrors that of the country-specific component: The lowest value corresponds to the Argentine crisis, whilst the highest coincides with the first symptoms of the global crisis.

\section{References}

Acemoglu D, Johnson S, Robinson JA, Thaicharoen Y (2003) Institutional causes, macroeconomic symptoms: volatility, crisis, and growth. J Monet Econ 50:49-122

Ahmed S (2003) Sources of economic fluctuations in Latin America and implications for choice of exchange rate regime. J Dev Econ 72:181-202

Aiolfi M, Catão L, Timmermann A (2010). Common factors in Latin America's business cycles. Discussion paper 7671, CEPR

Antonakakis N, Badinger H (2012). Output volatility, economic growth, and cross-country spillovers: new evidence for the G7 countries. Working paper 141, Department of Economics, University of Vienna

Athanasoulis S, van Wincop E (2000) Growth uncertainty and risk-sharing. J Monet Econ 45:477-505

Backus D, Kehoe P, Kydland F (1994) Dynamics of the trade balance and the terms of trade: the J-curve? Am Econ Rev 84:84-103

Baxter M, Kouparitsas M (2005) Determinants of business cycle comovement: a robust analysis. J Monet Econ 52:113-157

Bernard AB, Durlauf SN (1995) Convergence in international output. J Appl Econom 10:97-108

Blanchard O, Faruqee H, Das M (2010) The initial impact of the crisis on emerging market countries. Brook Pap Econ Act 41:263-323

Boschi M (2012) Long- and short-run determinants of capital flows to Latin America: a long-run structural GVAR model. Empir Econ 43:1041-1071

Boschi M, Girardi A (2011) The contribution of domestic, regional and international factors to Latin America's business cycle. Econ Model 28:1235-1246

Calvo G, Leiderman L, Reinhart C (1993) Capital flows and real exchange rate appreciations in Latin America. IMF Staff Pap 40:108-151

Canova F (2005) The transmission of US shocks to Latin America. J Appl Econom 20:229-251

Caporale GM, Ciferri D, Girardi A (2011) Fiscal shocks and real exchange rate dynamics: some evidence for Latin America. J Int Money Financ 30:709-723

Caporale GM, De Santis R, Girardi A (2014) Trade intensity and output synchronisation: on the endogeneity properties of EMU. J Financ Stabil. doi:10.1016/j.jfs.2014.01.003

Cesa-Bianchi A, Pesaran MH, Rebucci A, Xu T (2011). China's emergence in the world economy and business cycles in Latin America. Working paper 1150, Faculty of Economics, University of Cambridge

Contessi S, De Pace P, Guidolin M (2014) How did the financial crisis alter the correlations of US yield spreads? J Empir Financ 28:362-385

Diebold FX, Yilmaz K (2012) Better to give than to receive: predictive measurement of volatility spillovers. Int J Forecast 28:57-66

Forbes K, Rigobon R (2002) No contagion, only interdependence: measuring stock market co-movements. J Financ 57:2223-2261

Frankel J, Rose A (1998) The endogeneity of the optimum currency area criteria. Econ J 108:1009-1025

Granger CWJ (2008) Non-linear models: where do we go next-time varying parameter models? Stud Nonlinear Dyn Econom 12:1-9

Helbling T, Berezin P, Kose MA, Kumhof M, Laxton D, Spatafora N (2007). Decoupling the train? Spillovers and cycles in the global economy. World Econ Outlook 121-160

Imbs J (2003) Real effects of financial integration. Paper presented at the fourth annual IMF research conference, November 6-7

Imbs J (2010) The first global recession in decades. IMF Econ Rev 58:327-354

Izquierdo A, Romero R, Talvi E (2008). Booms and busts in Latin America: the role of external factors. Working paper 4569, IDB RES

Kalemli-Ozcan S, Papaioannou E, Peydro JL (2009). Financial integration and business cycle synchronization. Working paper 14887, NBER 
Kose MA, Yi K-M (2006) Can the standard international business cycle model explain the relation between trade and comovement? J Int Econ 68:267-295

Kose MA, Prasad ES, Terrones M (2003) How does globalization affect the synchronization of business cycles? Am Econ Rev 93:57-62

Kose MA, Otrok C, Prasad ES (2012) Global business cycles: convergence or decoupling? Int Econ Rev 53:511-538

Loayaza NV, Rancière R, Servén L, Ventura J (2007) Macroeconomic volatility and welfare in developing countries: an introduction. World Bank Econ Rev 21:343-357

Österholm P, Zettelmeyer J (2007) The effect of external conditions on growth in Latin America. Working papers $07 / 176$, IMF

Pesaran MH, Shin Y (1998) Generalized impulse response analysis in linear multivariate models. Econ Lett 58:17-29

Ramaswamy R, Sloek T (1998) The real effects of monetary policy in the European Union: what are the differences? IMF Staff Pap 45:374-402

Sims CA (1980) Macroeconomics and reality. Econometrica 48:1-47 